\title{
An experimental animal model for percutaneous procedures used in trigeminal neuralgia
}

\author{
Johannes Herta $^{1}$ - Wei-Te Wang ${ }^{1}$ - Romana Höftberger ${ }^{2}$ - Sabine Breit ${ }^{3}$. \\ Sibylle Kneissl $^{4} \cdot$ Helga Bergmeister ${ }^{5} \cdot$ Heber Ferraz-Leite ${ }^{1}$
}

Received: 8 October 2016/Accepted: 27 March 2017 / Published online: 10 April 2017

(C) The Author(s) 2017. This article is published with open access at Springerlink.com

\begin{abstract}
Object This study describes an experimental rabbit model that allows the reproduction of percutaneous operations that are used in patients with trigeminal neuralgia (TN). Attention was given to an exact anatomical description of the rabbit's middle cranial fossa as well as the establishment of conditions for a successful procedure.

Methods Morphometric measurements were taken from 20 rabbit skulls and CT scans. The anatomy of the trigeminal nerve, as well as its surrounding structures, was assessed by bilateral dissection of 13 New Zealand white rabbits (NWR). An ideal approach of placing a needle through the foramen ovale to reach the TG was sought. Validation of correct placement was realized by fluoroscopy and confirmed by dissection.

Results Precise instructions for successful reproduction of percutaneous procedures in NWR were described.
\end{abstract}

Electronic supplementary material The online version of this article (doi:10.1007/s00701-017-3162-8) contains supplementary material, which is available to authorized users.

Johannes Herta

johannes.herta@meduniwien.ac.at

1 Department of Neurosurgery, Medical University of Vienna, Vienna, Austria

2 Institute of Neurology, Medical University of Vienna, Vienna, Austria

3 Department of Pathobiology, University of Veterinary Medicine, Vienna, Austria

4 Diagnostic Imaging, Department for Companion Animals and Horses, University of Veterinary Medicine, Vienna, Austria

5 Department of Biomedical Research, Medical University of Vienna, Vienna, Austria
According to morphological measurements, for balloon compression of the trigeminal ganglion (TG) the maximal diameter of an introducing cannula is $1.85 \mathrm{~mm}$. The diameter of an empty balloon catheter should not exceed $1.19 \mathrm{~mm}$, and the length of the inflatable part of the balloon can range up to $4 \mathrm{~mm}$. For thermocoagulation the needle electrodes must not exceed an external diameter of $1.39, \mathrm{~mm}$ and the length of the non-insolated tip can range up to $4 \mathrm{~mm}$. Glycerol rhizolysis can be achieved because the trigeminal cistern in the NWR is a closed space that allows a long dwelling time $(>10 \mathrm{~min})$ of the contrast agent.

Conclusions An experimental NWR model intended for the reproduction of percutaneous procedures on the TG has been meticulously described. This provides a tool that enables further standardized animal research in the field of surgical treatment of TN.

Keywords Animal model · Trigeminal neuralgia $\cdot$ Balloon compression · Glycerol rhizolysis · Thermocoagulation . Percutaneous procedures

$\begin{array}{ll}\text { Abbreviations } \\ \text { BC } & \begin{array}{l}\text { Percutaneous balloon compression } \\ \text { EOP }\end{array} \\ \begin{array}{ll}\text { External occipital protuberance (protuberantia } \\ \text { occipitalis externa) }\end{array} \\ \text { FAC } & \text { Foramen alare caudale } \\ \text { FO } & \text { Foramen ovale } \\ \text { GR } & \text { Percutaneous glycerol rhizolysis } \\ \text { NWR } & \text { New Zealand white rabbits } \\ \text { OF } & \text { Orbital fissure (fissura orbitalis) } \\ \text { PI- } & \text { Line between the external occipital protuberance and } \\ \text { Line } & \text { incisive bone } \\ \text { TC } & \text { Percutaneous radiofrequency-thermocoagulation }\end{array}$

Abbreviations

BC Percutaneous balloon compression

FAC Foramen alare caudale

FO Foramen ovale

GR Percutaneous glycerol rhizolysis

NWR New Zealand white rabbits

OF Orbital fissure (fissura orbitalis)

PI- Line between the external occipital protuberance and

TC Percutaneous radiofrequency-thermocoagulation 


$\begin{array}{ll}\text { TCI } & \text { Trigeminal cistern (cisterna trigemini) } \\ \text { TG } & \text { Trigeminal ganglion (ganglion trigeminale) } \\ \text { TN } & \text { Trigeminal neuralgia } \\ \text { TNC } & \text { Trigeminal nerve canal (canalis nervi trigemini) } \\ \text { V1 } & \text { Ophthalmic nerve (nervus ophthalmicus) } \\ \text { V2 } & \text { Maxillary nerve (nervus maxillaris) } \\ \text { V3 } & \text { Mandibular nerve (nervus mandibularis) } \\ \times 1 & \text { Dorsoventral plane } \\ \times 2 & \text { Transverse plane } \\ \times 3 & \text { Sagittal plane }\end{array}$

\section{Introduction}

In trigeminal neuralgia (TN), surgical therapies are applied if medication is ineffective or if adverse effects exceed the benefits of drugs [5]. Besides microvascular decompression introduced by Jannetta in 1967, less invasive procedures with the aim of adding a lesion to the trigeminal ganglion (ganglion trigeminale, TG) are commonly used: percutaneous balloon compression (BC), percutaneous radiofrequencythermocoagulation (TC) and percutaneous glycerol rhizolysis (GR) $[6,9,14,19]$. All three procedures share the same approach to the TG. A cannula is inserted percutaneously near the corner of the mouth, and by means of X-ray fluoroscopy, controlled advancement to the foramen ovale (FO) is thereby made possible. Subsequently, the TG and/or the trigeminal nerve root is partly damaged by compression, thermocoagulation or toxicity of glycerol.

Despite the frequent use of these surgical procedures, little is known about the arising pathophysiological changes in the trigeminal system. To reveal these changes, several attempts have been made to create animal models. But experimental setups that came close to operations in humans were rare, and the majority of experiments were conducted on and around peripheral nerves and not at the TG $[4,7,13$, $15,17,18,20]$. Therefore, dogs were used only once to reproduce GR and TC, while New Zealand white rabbits (NWR) were used in three experimental studies for BC. Noteworthily, histological findings have been partly contradictory and a standardization of the experiments is still needed $[3,8,11,12,16]$.

Preul et al. [16] used a rabbit model to simulate percutaneous procedures on the TG. But a thorough description of the anatomy as well as the used materials and methods is necessary to use their model. The present study aims to create a manual for reproducible percutaneous operations on the TG in NWR in order to unify further research. The conditions for a successful procedure were derived after dissections and morphometric measurements.

\section{Methods}

After a preliminary morphometric study, we concluded that rabbits seem to be the most suitable animal to reproduce percutaneous procedures at the TG. Not only is the anatomical accessibility to the TG feasible, but also costs are moderate and the Animal Welfare Act allows experimentation with rabbits in most European countries.

\section{Preliminary CT measurements}

Twenty cranial CT scans, performed in rabbits with toothache at the department of Diagnostic Imaging, University of Veterinary Medicine, Vienna, were reviewed to measure the size of their 40 foramina ovalia and other related anatomical landmarks (Table 1). Images were acquired by a Somatom Emotion 16 Scanner (Siemens). The multi-slice data set was made with a thickness of $750 \mu \mathrm{m}$ and evaluated on a Multimodality Workplace (Syngo, Siemens). To compensate for different skull sizes, a linear regression analysis was conducted to find a relationship between the length of the skull defined by the distance between the external occipital protuberance (protuberantia occipitalis externa, EOP) and the incisive bone (os incisivum), as well as the weight of the animals.

\section{Anatomical measurements under the microscope and histological localization of the trigeminal ganglion}

Thirteen heads of NWRs with a mean weight of $2.10 \pm 0.78 \mathrm{~kg}$ were dissected to obtain measurements of anatomical structures and their relationships in the middle cranial fossa. All rabbits had been used and killed in previous animal experiments with a valid approval of the Commission for Animal Experimentation, leaving the skull and the brain intact. Dissection was performed in the operating rooms of the Department of Biomedical Research. Measurements, illustrated in Fig. 1, were performed under an operating microscope with a digital vernier caliper (Kinzo; Type: 12W68). Besides that, eight intracranial trigeminal nerves of four animals were harvested, inlaid in $10 \%$ formalin and further processed at the Institute of Neurology for histological confirmation of the localization of the TG. Each probe was cut in multiple sections [brainstem, trigeminal nerve root, TG, mandibular nerve (n. mandibularis, V3), maxillary nerve (n. maxillaris, V2) and ophthalmic nerve (N. ophthalmicus, V1)] and subsequently stained with HE, SMI31, SSB, CD68 and toluidine blue.

\section{Simulation of percutaneous procedures in cadavers}

A percutaneous placement of a cannula through the cheek to reach the FO, as done in humans, is not possible in rabbits. For this reason, we switched to a submandibular approach and performed 30 percutaneous procedures (20 
Table 1 CT measurements taken from 20 rabbits $(2.10 \pm 0.78 \mathrm{~kg})$

\begin{tabular}{|c|c|c|c|c|}
\hline Measure & Landmark & Plane & Orientation/description & Results \\
\hline Distance & Left to right facial tuberosity & $\mathrm{X} 1$ & Inner surface; most rostral point & $31.85 \pm 3.17 \mathrm{~mm}$ \\
\hline Distance & Left to right jugular process & $\mathrm{X} 2$ & Inner surface; most rostral point & $24.33 \pm 2.86 \mathrm{~mm}$ \\
\hline Distance & Left to right FO & $\mathrm{X} 2$ & Median of both foramina & $8.35 \pm 0.79 \mathrm{~mm}$ \\
\hline Distance & $\mathrm{FO}$ to $\mathrm{OF}$ & $\mathrm{X} 1$ & FO rostral surface; OF caudal surface & $6.19 \pm 1.05 \mathrm{~mm}$ \\
\hline Distance & FOR to TNC & $\mathrm{X} 1$ & FOR caudal surface; TNC rostral surface & $8.36 \pm 1.01 \mathrm{~mm}$ \\
\hline Distance & FO to mandibular angle & $\mathrm{X} 2$ & $\begin{array}{l}\text { Median surface FO; lower, median surface } \\
\text { angulus mandibulae }\end{array}$ & $33.75 \pm 7.78 \mathrm{~mm}$ \\
\hline Distance & $\mathrm{FO}$ to $\mathrm{FAC}$ & $\mathrm{X} 1$ & FAC caudal surface, FO rostral surface, & $5.27 \pm 0.91 \mathrm{~mm}$ \\
\hline Distance & EOP to incisive bone (PI-line) & $\mathrm{X} 1$ & Most distant points in the midline & $87.16 \pm 11.07 \mathrm{~mm}$ \\
\hline Diameter & $\mathrm{FO}$ & $\begin{array}{l}\mathrm{X} 2 \text { tilted to be perpendicular } \\
\text { to the foramen }\end{array}$ & Inscribed circle of the FO (triangle shape) & $2.13 \pm 0.28 \mathrm{~mm}$ \\
\hline Diameter & $\mathrm{TNC}$ & $\begin{array}{l}\mathrm{X} 2 \text { tilted to be perpendicular } \\
\text { to the canal }\end{array}$ & $\begin{array}{l}\text { Inscribed circle of the TNC (oval shape, } \\
\text { width used) }\end{array}$ & $2.32 \pm 0.37 \mathrm{~mm}$ \\
\hline Angle & Angle of puncturing needle & $\mathrm{X} 3$ & $\begin{array}{l}\text { Entry point }=\text { caudo-median surface of the } \\
\text { mandibular angle, target = caudal surface } \\
\text { of the FO }\end{array}$ & $73.23 \pm 12.23^{\circ}$ \\
\hline
\end{tabular}

$\mathrm{FO}=$ foramen ovale, $\mathrm{OF}=$ orbital fissure, $\mathrm{TNC}=$ trigeminal nerve canal, $\mathrm{FAC}=$ foramen alare caudale, $\mathrm{EOP}=$ external occipital protuberance $\mathrm{X} 1=$ dorsoventral, $\mathrm{X} 2=$ transverse, $\mathrm{X} 3=$ sagittal

TC, 6 BC, 4 GR) in 16 NWR cadavers. Optimal needle placement was ensured by radiographs and subsequent cranial dissections. Because we aimed to provide a manual for experimental percutaneous procedures, the methods and used equipment are described in the results section.

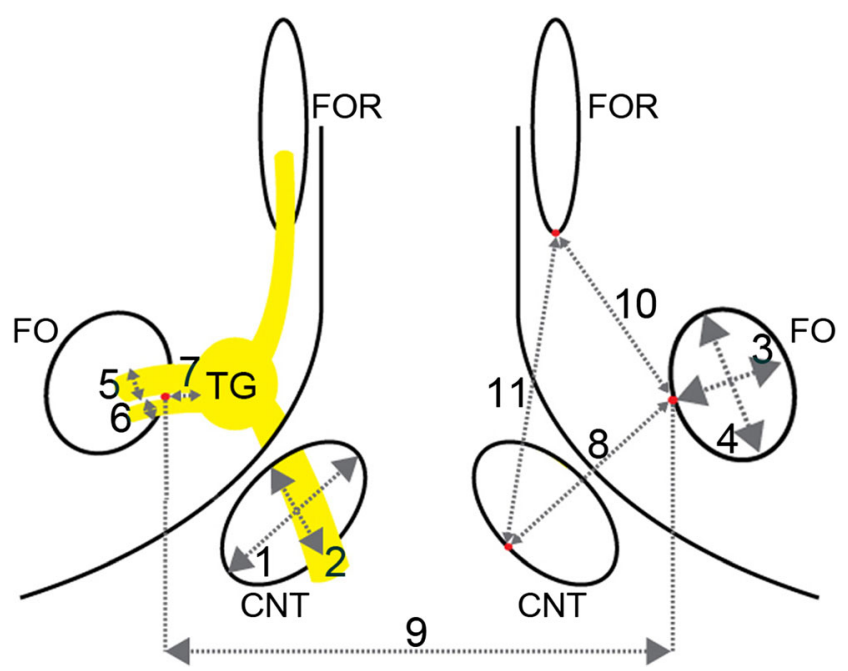

Fig. 1 Schematic illustration of the middle cranial fossa in a dorsal view. Measurements, which were taken in the middle cranial fossa of $13 \mathrm{New}$ Zealand white rabbits, are illustrated. Width of TNC (1) and FO (3), height of TNC (2) and FO (4), diameter of V3 (5) and V3 motor branch (6), distance between: medial limit FO and lateral limit TG (7), medial limit FO and medial limit TNC (8), medial limit FO and medial limit FO (9), caudal limit OF and medial limit FO (10) and caudal limit OF and medial limit TNC (11). FO, foramen ovale; TNC, trigeminal nerve canal; V3, mandibular nerve; TG, trigeminal ganglion; OF, orbital fissure

\section{Results}

\section{CT measurements}

The mean weight of the rabbits was $2.10 \pm 0.78 \mathrm{~kg}$. CT measurements are listed in detail in Table 1. The mean inscribed circle radius of the $\mathrm{FO}$ was measured to be $2.13 \pm 0.28 \mathrm{~mm}$, while the mean inscribed circle radius of the trigeminal nerve canal (canalis nervi trigemini, TNC) was $2.32 \pm 0.37 \mathrm{~mm}$. There was a correlation between the radius of the FO and the weight of the rabbits $(r=0.54)$ as well as the mean distance between EOP and incisive bone $(r=0.67)$, left and right facial tuberosity $(r=0.65)$ and left and right jugular process $(r=0.44)$.

The trajectory of a puncturing cannula with the entry point at the anterior border of the mandibular angle and the FO as a target has an angle of $44.1 \pm 3.21^{\circ}$ in relation to the dorsoventral plane $(\times 1)$. Accordingly, in relation to the transverse plane $(\times 2)$, an angle of $73.23 \pm 12.23^{\circ}$ was measured. The cannula must be at least $41.53 \mathrm{~mm}$ long to reach the FO as shown by the distance between the FO and mandibular angle.

\section{Anatomical dissection, measurements and histological verification of the trigeminal ganglion}

Anatomical dissections were performed in 13 NWRs with a mean weight of $4.09 \pm 0.6 \mathrm{~kg}$. Detailed illustrations of dissections are available online as Supplemental material. Accordingly, Fig. 2 not only serves as a legend but illustrates the anatomical relationships by giving morphometric measurements of the middle cranial fossa and the TG in NWR. 
Fig. 2 Anatomic schema and measures of middle cranial fossa structures, carried out by bilateral dissections in 13 New Zealand white rabbits

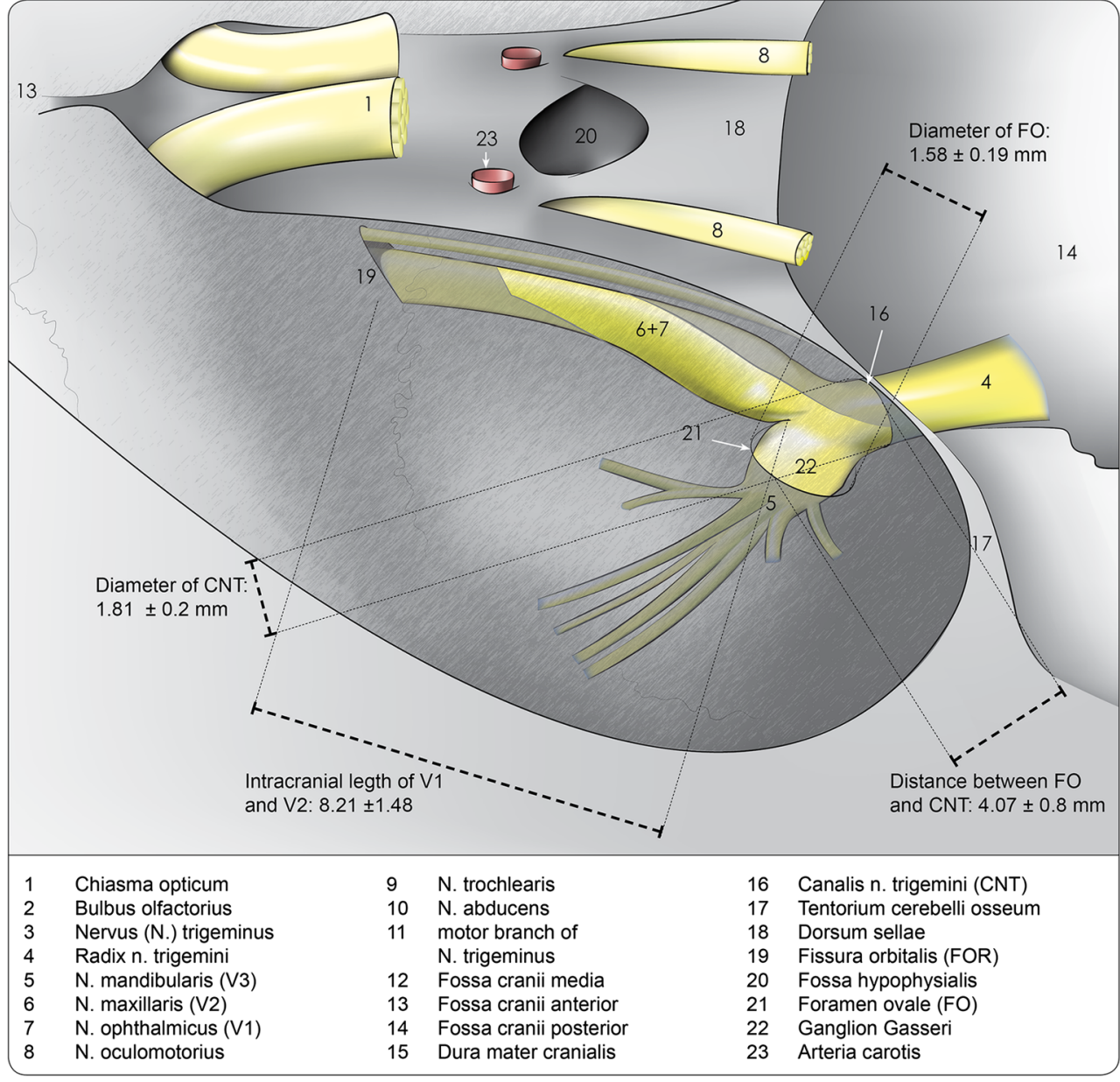

The FO had a mean length of $2.68 \pm 0.33 \mathrm{~mm}$ and a mean width of $1.58 \pm 0.19 \mathrm{~mm}$. Thus, the diameter of a puncturing cannula must be smaller than $1.39 \mathrm{~mm}$, equivalent to an $18-\mathrm{G}$ needle. The TNC had a length of $1.81 \pm 0.20 \mathrm{~mm}$ and a width of $3.23 \pm 0.40 \mathrm{~mm}$. The risk of puncturing the brainstem through the TNC is nearly zero because of an obtuse angle with the FO. The distance between the FO and the orbital fissure $(\mathrm{OF})$ is representative for the intracranial length of V1 and V2, which leave the cranial cavity together through the OF. The distance between the FO and the TNC of approximately $4 \mathrm{~mm}$ indicates the needed length for compressing balloons or coagulating electrode tips.

Histological examination of eight TG and corresponding nerves in rabbits showed a similar localization to humans. No signs of damage due to manipulation could be seen.

\section{Conditions for a successful procedure}

The following conditions should be fulfilled for a successful procedure in NWR.

\section{Percutaneous radiofrequency thermocoagulation (TC):}

- Needle electrodes for TC should not exceed a diameter of $1.39 \mathrm{~mm}$. A cannula smaller than $18 \mathrm{G}$ should be used.

- The length of the non-insulated part of the needle electrode should not exceed a length of $3.27 \mathrm{~mm}$.

- The length of the puncturing cannula needs to be longer than $45 \mathrm{~mm}$.

\section{Percutaneous balloon compression (BC):}

- An inserting cannula for $\mathrm{BC}$ should have a maximal diameter of $16 \mathrm{G}$. According to the measures obtained with dissections and CT scans, an outer diameter size between $1.39 \mathrm{~mm}$ and $1.85 \mathrm{~mm}$ is needed to reach slightly into the FO.

- The possible diameter for a deflated balloon is depending on the inserting cannula used. A normal $18-\mathrm{G}$ needle has an inner diameter of approximately $0.838 \mathrm{~mm}$; a $16-\mathrm{G}$ needle has an inner diameter of $1.194 \mathrm{~mm}$. However, there are also "thin wall" needles with a wider inner diameter 
Fig. 3 A: Important landmarks to reach the FO with a cannula. B: Common possibilities of false needle placement on the left. If the needle is correctly placed through the FO (B, right side) there is still a risk of perforating the dura mater and the temporal lobe (C, arrow)

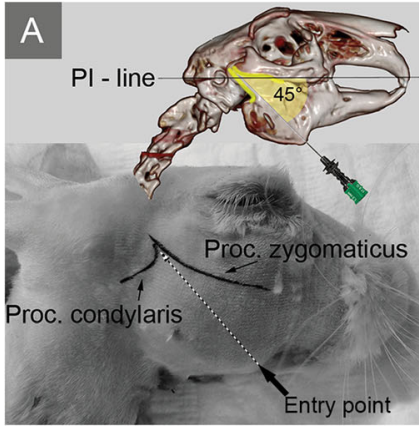

available.

- The length of the inserting cannula needs to be longer than $45 \mathrm{~mm}$.

- Balloon size should not exceed the distance between the FO and TNC. This means a balloon should be smaller than $4.07 \pm 0.8 \mathrm{~mm}$ long.

\section{Percutaneous glycerol rhizolysis (GR):}

- The puncturing needle should be longer than $45 \mathrm{~mm}$ and should not exceed an outer diameter of $18 \mathrm{G}$.



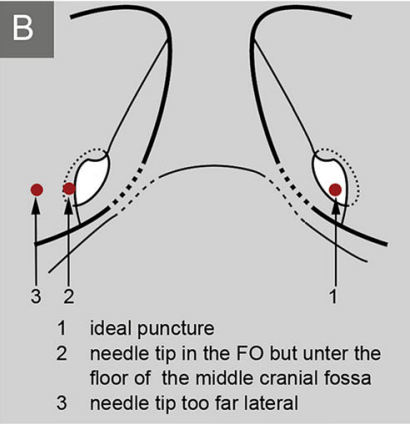

- The trigeminal cistern (TCI) is a closed cavity in NWR. The anatomical circumstances are very tight, and only small amounts of glycerol can be injected.

\section{Puncture technique and procedures}

Positioning and orientation The rabbit is placed in a prone position with a rotated head. The head is shaved, and landmarks are marked as shown in Fig. 3A. In the lateral view, the $\mathrm{FO}$ projects approximately at the inter-

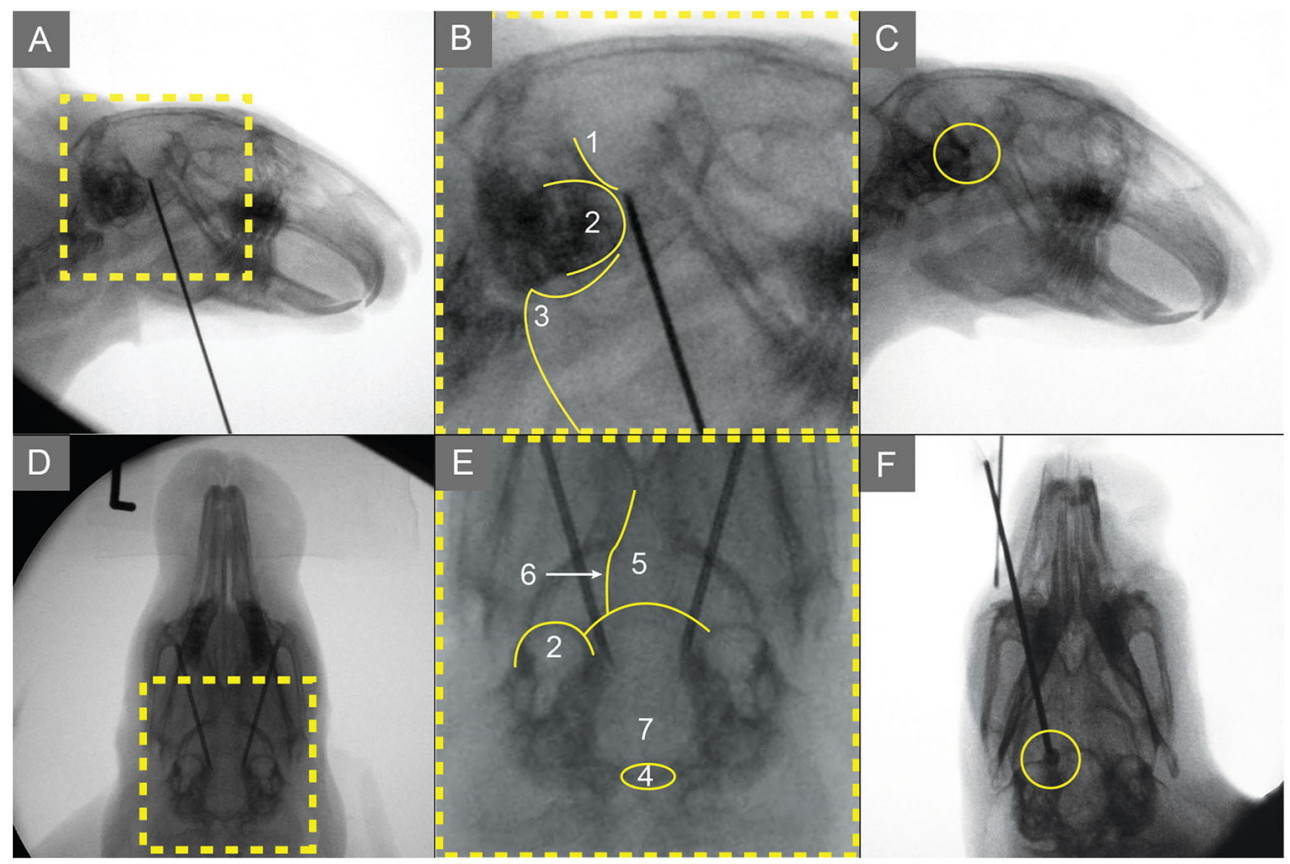

Fig. 4 Fluoroscopy is used to confirm correct needle placement while puncturing a New Zealand white rabbit. A and B: Sagittal projection of the head with the needle advanced maximally into the trigeminal cistern (TCI). Further advancement would cause a perforation of the dura mater. $\mathrm{D}$ and E: The same head in a dorsoventral projection. Correct needle placement can be confirmed only by checking both planes. C:
Simulation of glycerol rhizolysis by injecting contrast agent into the TCI. The radiological control shows the remaining contrast agent 10 min after the injection. F: Correct placement of a balloon catheter. 1, osseous cerebellar tentorium; 2 , tympanic cavity; 3 , mandibular angular process; 4 , foramen magnum; 5 , basisphenoid bone; 6 , pterygoid bone; 7 , occipital bone 




Fig. 5 Modified equipment for percutaneous balloon compression (BC). 1: Guiding cannula for BC: Angiotech ${ }^{\circledR}$ CAN $16 \mathrm{G} 10 \mathrm{~cm} 2$ 2) Fogarty ${ }^{\circledR}$ no. 2 embolectomy catheter with a proximal ligated balloon and (3) distal tip cut for reduction of length. (4) It is important to mark the catheter length to be inserted into the trigeminal cistern in order to accomplish an exact advancement of the balloon out of the cannula tip

section of the lower rim of the zygomatic arch and the rear rim of the condylar process (processus condylaris). The entry point for the cannula is laterally projected at the prominence of the mandibular angle.

Puncture procedure (Fig. 3A) The entry of the cannula is precisely at the inner rim of the lower jaw. The cannula is advanced at a 45 degree angle to the PI-Line in the direction of the FO.. Under sagittal fluoroscopy the needle is advanced with an angle of 10 to $15^{\circ}$ to the dorsoventral plane $(\times 1)$. Correct needle placement should be assessed in the dorsoventral $(\times 1)$ as well as sagittal $(\times 3)$ plane as shown in Fig. 4 A, B, $\mathrm{D}$ and $\mathrm{E}$.

Source of error It is important to advance the needle without any resistance. When it is felt, fluoroscopy should confirm correct needle placement. If the cannula is placed too far lateral from the FO, it can be entangled in the poriferous base of the sphenoid bone. Respectively, it can be blocked in a small prominence of the middle cerebral fossa that partly overlaps laterally with the FO (Fig. 3B). In these cases, the position of the cannula can be adjusted more medially. If the cannula passes abruptly through the FO, there is a possibility of perforation of the dura mater and temporal lobe as seen in Fig. 3C.

Percutaneous balloon compression (BC) For the simulation of $\mathrm{BC}$ we used Fogarty ${ }^{\circledR}$ No.2 embolectomy catheters of different brands (Edwards Lifesciences ${ }^{\mathrm{TM}}$, LeMaitre ${ }^{\circledR}$ ). These catheters have short balloon and catheter tip lengths but still exceed the length of the TCI $(4.07 \pm 0.8 \mathrm{~mm})$.

Therefore, we modified the LeMaitre ${ }^{\circledR}$ catheter as shown in Fig. 5. Under the operating microscope, the proximal part of the balloon was ligated with four 7-0 Ethicon $\AA$ ligatures. The catheter tip was cut. Via this method, we could achieve a balloon length of less than $5 \mathrm{~mm}$. As a guiding cannula, a 16-G Angiotech ${ }^{\circledR}$ biopsy needle was used. The Edwards Lifesciences $^{\mathrm{TM}}$ catheter has a balloon and tip length of $7 \mathrm{~mm}$ and is overall more flexible. No modifications were used. As a guiding cannula, a 14-G Vasofix ${ }^{\circledR}$ Safety cannula was used. Before starting the procedure, it is important to mark the catheter length to be inserted into the TCI to accomplish an exact advancement of the balloon out of the cannula tip. The guiding cannula tip is placed at the entrance of the FO. Afterwards, the balloon catheter is advanced until the balloon completely exits the cannula, which is verified by the previously made mark. The balloon cannot be inflated until its optimal position has been reached. Otherwise the sharp guiding cannula could damage the balloon. Correct placement is again verified by fluoroscopy (Fig. 4F). After the BC has been achieved, the balloon is deflated and removed together with the guiding cannula.

Percutaneous glycerol rhizolysis (GR) NWRs have a closed TCI, and GR can be simulated. We injected up to $0.5 \mathrm{ml}$ of contrast agent (Jopamiro ${ }^{\circledR}$ ) and confirmed radiological permanence in the TCI after 5 to $10 \mathrm{~min}$ in four NWRs (Fig. 4C). Only small amounts of contrast agent are applicable, and most of the $0.5 \mathrm{ml}$ we injected was lost in the empty space of the cannula or spread out of the TCI into the posterior fossa or back out of the FO.

\section{Discussion}

To better understand the histopathological changes that occur after percutaneous surgical procedures in TN patients, animal experimentation is required. To this day two animal models that reproduce these procedures in mongrel dogs and NWR have been published. Kanpolat described and accurately illustrated the technique used in dogs [10]. But because most European countries prohibit animal experimentation with dogs, in our study we focused on the NWR model introduced by Preul et al. in 1990 [16]. Rabbits seem to be the most appropriate animals for percutaneous procedures. The advantages here are obvious: (1) rabbits are frequently used in experimental research; (2) their cost for experimental research is relatively low; (3) they have an adequately sized FOs; (4) harvesting their fairly large trigeminal nerves is easily carried out; (5) their use for experimental research is not prohibited by law in most European countries; (6) dropout rates in former studies were acceptable $[12,16]$.

Our initial idea was to perform a histopathological examination after BC. However, when we carried out our preliminary tests on NWR cadavers, we found that the insertion of a needle to the FO as well as further $\mathrm{BC}$ had some difficulties. First, our prior knowledge of the anatomy of the trigeminal system in rabbits was 
very limited, and to our knowledge exact measurements and anatomical descriptions of the middle cranial fossa in rabbits have not been published. Second, in preexisting studies the technique of the puncture itself, the positioning of the animal, landmarks to guide the insertion of the needle under fluoroscopy as well as used materials were inadequately described and illustrated to allow reproduction. To answer these questions in the present study, we obtained accurate morphometric measures in fresh NWR cadavers as well as on rabbit CT scans. Histological proof of the presence and location of the TG was given. The technique of the three most common percutaneous procedures at the TG of rabbits has been described in detail.

\section{Percutaneous balloon compression (BC)}

We found that compression of the TG in the TCI without damaging nearby structures is possible but hampered by inadequately sized equipment. It should be noted that Fogarty ${ }^{\circledR}$ no. 2 embolectomy catheters differ in balloon and catheter tip size, shape and rigidity per different supplier. Even by modification of the Fogarty ${ }^{\circledR}$ no. 2 catheter to a minimal balloon length of $5 \mathrm{~mm}$, its large size was not optimal for $\mathrm{BC}$ in rabbits. All three previously reported $\mathrm{BC}$ experiments $[3,12,16]$ used Fogarty ${ }^{\circledR}$ no. 2 embolectomy catheters with tip lengths larger than the TCI. An adaptation of the catheter to the anatomical conditions was not described by the authors. Furthermore, they used catheter insertion depths beyond the FO of 4-6 $\mathrm{mm}$ and 3-5 mm, respectively, while in our measurements the possible insertion depths should not exceed $4.07 \pm 0.8 \mathrm{~mm}$. Here, it has to be stressed that Preul et al. as well as Brown et al. used larger NWRs $(2.5-3.9 \mathrm{~kg} / 2.5-4.4 \mathrm{~kg}$ vs. $1.3-2.9 \mathrm{~kg}$ ), which could imply a larger TCI. Brown et al. [3] observed that the catheter tip was advanced into the TNC and assumed that trigeminal nerve root damage should be considered as one of the mechanisms involved in the physiopathological effects of $\mathrm{BC}$. We found that the TNC (which is referred to as porus trigeminus in Preul's work [16]) is a tight channel whose axis is at an acute angle with the axis of the FO. The relatively rigid catheter we used did not change the direction after introduction into the TCI as shown by postoperative dissections.

The extent to which $\mathrm{BC}$ in rabbits is comparable to percutaneous procedures in human beings still needs to be assessed. This is not only due to the absence of disease in the animals, but also due to the different anatomy in rabbits. Their TG is nearly completely embedded in bone, as shown in Fig. 2. Nevertheless comparable compression pressures between 829 and $1179 \mathrm{mmHg}$ in NWR $[12,16]$ and 1140 $1216 \mathrm{mmHg}$ in humans [2] seem feasible.

\section{Percutaneous glycerol rhizolysis (GR)}

Among percutaneous procedures, the effect of GR on the nervous system is probably the most commonly studied and at the same time controversially discussed $[1,4,6-8,13,15,17,18$, 20]. Furthermore, it remains necessary to clarify which fibers are damaged by different concentrations of glycerol.

In our study, we managed to inject contrast agent into the TCI. The contrast agent remained in place for longer than $10 \mathrm{~min} ; 0.5 \mathrm{ml}$ was used, which may seem a lot since Hakanson described 0.2-0.4 $\mathrm{ml}$ in humans [6]. Far smaller amounts are possible in rabbits, but we encountered loss of contrast agent into the posterior fossa as well as residues in the cannula in all four cases.

So far, the study of Isik et al. [8] is the only glycerol experiment that used a percutaneous technique at the TG of dogs. The technique used is analogous to the surgical technique introduced by Hakanson [6] in humans. Even here, the experiment cannot be adopted one to one to humans because, according to Isik et al. [8], the TCI is missing in dogs. Thus, glycerol was injected topically into the TG and not into a cistern.

\section{Percutaneous radiofrequency thermocoagulation (TC)}

TC, developed by Sweet [19], can be easily reproduced in rabbits. He proposed that the main mechanism of TC in $\mathrm{TN}$ is the selective destruction of thin and nonmyelinated A- $\delta$ and $\mathrm{C}$ fibers at $60-80{ }^{\circ} \mathrm{C}$, which would interrupt pain transmission while maintaining sensitivity. This assumption is contradicted by a study by Kanpolat [11] who carried out TC in dogs and observed no restriction to certain fibers. Of interest and important for future experiments was the finding that in both percutaneous experiments with dogs accidental puncture of the internal carotid artery occurred $[8,11]$. This is another reason for preferring rabbits over dogs for an experimental model. Puncture of the internal carotid artery in rabbits is nearly impossible because of a more caudally located artery and the interposed hard basisphenoid bone. Nevertheless, we do not advise the use of smaller rabbits because of a higher risk of accidental puncture of the maxillary artery, which enters the foramen alare caudale (FAC) in the vicinity of the FO.

\section{Limitations}

Morphometric measurements in unfixed cadavers always feature a bias due to quickly occurring cell death. Therefore, we only used fresh NWR cadavers and performed dissections in a fast and standardized way. 


\section{Conclusion}

Percutaneous procedures at the TG of rabbits under fluoroscopy were described in detail after carrying out morphometric measurements. This technique enables us to perform percutaneous operations at the TG in a reproducible way compared to how they are carried out in humans suffering from TN. Thus, the histological and pathophysiological changes in the trigeminal system after BC, TC and GR can be examined. While TC and GR are easy to reproduce in rabbits, $\mathrm{BC}$, due to the tight conditions in the TCI, remains a challenge that can be overcome with an adequately small balloon catheter size.

Our model provides the possibility to assess the effect of variable parameters, such as coagulation time and temperature in TC, compression time and pressure in $\mathrm{BC}$ and alcohol concentration in GR. These parameters have frequently been discussed in the literature, but mainly by comparing clinically effects and not by comparing morphological changes on the nerve. This standardized model may allow a better understanding of the mechanisms involved and verify whether and which fibers are affected by ablative procedures. We expect that in the future and based on our detailed descriptions of a rabbit model, the knowledge gained will help improve the surgical treatment results and prognosis of percutaneous procedures on the TG.

Acknowledgements Open access funding provided by Medical University of Vienna.

\section{Compliance with ethical standards}

Funding No funding was received for this research.

\section{Conflict of interest None}

Animal experiments All applicable international, national, and/or institutional guidelines for the care and use of animals were followed.

All procedures performed in studies involving animals were in accordance with the ethical standards of the institution or practice at which the studies were conducted.

Open Access This article is distributed under the terms of the Creative Commons Attribution 4.0 International License (http:// creativecommons.org/licenses/by/4.0/), which permits unrestricted use, distribution, and reproduction in any medium, provided you give appropriate credit to the original author(s) and the source, provide a link to the Creative Commons license, and indicate if changes were made.

\section{References}

1. Bremerich A, Reisert I (1991) Perineural application of glycerol and phenol-glycerol. Histomorphologic-morphometric study. Dtsch Zahnarztl Z 46:825-827
2. Brown JA, Pilitsis JG (2005) Percutaneous balloon compression for the treatment of trigeminal neuralgia: results in 56 patients based on balloon compression pressure monitoring. Neurosurg Focus 18: E10

3. Brown JA, Hoeflinger B, Long PB, Gunning WT, Rhoades R, Bennett-Clarke CA, Chiaia NL, Weaver MT (1996) Axon and ganglion cell injury in rabbits after percutaneous trigeminal balloon compression. Neurosurgery 38:993-1003 discussion 1003-1004

4. Burchiel KJ, Russell LC (1985) Glycerol neurolysis: neurophysiological effects of topical glycerol application on rat saphenous nerve. J Neurosurg 63:784-788

5. Gronseth G, Cruccu G, Alksne J, Argoff C, Brainin M, Burchiel K, Nurmikko T, Zakrzewska JM (2008) Practice parameter: the diagnostic evaluation and treatment of trigeminal neuralgia (an evidence-based review): report of the Quality Standards Subcommittee of the American Academy of Neurology and the European Federation of Neurological Societies. Neurology, vol 71. Lippincott Williams \& Wilkins, pp 1183-1190

6. Håkanson S (1981) Trigeminal neuralgia treated by the injection of glycerol into the trigeminal cistern. Neurosurgery 9:638-646

7. Hara H, Kobayashi S (1992) Glycerol injection to the rat trigeminal nerve: histological and immunohistochemical studies. Acta Neurochir 119:111-114

8. Isik N, Pamir MN, Benli K, Erbengi A, Erbengi T, Ruacan S (2002) Experimental trigeminal glycerol injection in dogs: histopathological evaluation by light and electron microscopy. Stereotact Funct Neurosurg 79:94-106

9. Jannetta PJ (1967) Arterial compression of the trigeminal nerve at the pons in patients with trigeminal neuralgia. J Neurosurg 26(Suppl):159-162

10. Kanpolat $Y$ (1979) Percutaneous approach to the trigeminal ganglion in dogs. J Neurosci Methods 1:375-381

11. Kanpolat Y, Onol B (1980) Experimental percutaneous approach to the trigeminal ganglion in dogs with histopathological evaluation of radiofrequency lesions. Acta Neurochir Suppl (Wien) 30:363-366

12. Li F, Han S, Ma Y, Yi F, Xu X, Liu Y (2014) Optimal duration of percutaneous microballoon compression for treatment of trigeminal nerve injury. Neural Regen Res 9:179-189

13. Lunsford LD, Bennett MH, Martinez AJ (1985) Experimental trigeminal glycerol injection. Electrophysiologic and morphologic effects. Arch Neurol 42:146-149

14. Mullan S, Lichtor T (1983) Percutaneous microcompression of the trigeminal ganglion for trigeminal neuralgia. J Neurosurg 59:10071012

15. Pal HK, Dinda AK, Roy S, Banerji AK (2009) Acute effect of anhydrous glycerol on peripheral nerve: an experimental study. Br J Neurosurg 3:463-469

16. Preul MC, Long PB, Brown JA, Velasco ME, Weaver MT (1990) Autonomic and histopathological effects of percutaneous trigeminal ganglion compression in the rabbit. J Neurosurg 72:933-940

17. Rengachary SS, Watanabe IS, Singer P, Bopp WJ (1983) Effect of glycerol on peripheral nerve: an experimental study. Neurosurgery 13:681-688

18. Stajcić Z (1991) Effects of glycerol on the rat infraorbital nerve: an experimental study. Br J Oral Maxillofac Surg 29:90-93

19. Sweet WH, Wepsic JG (1974) Controlled thermocoagulation of trigeminal ganglion and rootlets for differential destruction of pain fibers. 1. Trigeminal neuralgia. J Neurosurg 40:143-156

20. Vallat JM, Leboutet MJ, Loubet A, Hugon J, Moreau JJ (1988) Effects of glycerol injection into rat sciatic nerve. Muscle Nerve 11:540-545 